Revista Brasileira de Agricultura Irrigada v.8, nº. 3, p. 296 - 307, 2014

ISSN 1982-7679 (On-line)

Fortaleza, CE, INOVAGRI - http://www.inovagri.org.br

DOI: $10.7127 /$ rbai.v8n300216

Protocolo 216/14 - 15/01/2014 Aprovado em 13/03/2014

\title{
PRODUTIVIDADE E TEORES DE NUTRIENTES EM GRÃOS DE FEIJÃO SOB DIFERENTES MANEJO DO SOLO E DA IRRIGAÇÃO*
}

\author{
José Joaquim Carvalho ${ }^{1}$, Nelmício Furtado da Silva ${ }^{2}$, Diego Martins Alves ${ }^{3}$, Wilker Alves \\ Morais ${ }^{4}$, Fernando Nobre Cunha ${ }^{5}$, Marconi Batista Teixeira ${ }^{6}$
}

\begin{abstract}
RESUMO
A agricultura irrigada tem sido importante estratégia na otimização da produção mundial de alimentos, proporcionando desenvolvimento sustentável no campo, com geração de empregos e renda de forma estável. Nos cultivos irrigados, tornam-se evidente e a necessidade do gerenciamento da lâmina aplicada pelos sistemas de irrigação, pois sua utilização apresenta desde melhoria no incremento produtivo e na qualidade dos grãos e, ao mesmo tempo, maximizar a eficiência do uso da água. O sistema deve possibilitar que a água seja aplicada uniformemente as plantas, no momento oportuno e na quantidade adequada. As irrigações devem ser realizadas antes que a deficiência de água no solo possa comprometer as atividades fisiológicas das plantas e causar decréscimo na produção. $\mathrm{O}$ experimento foi conduzido na área experimental do Departamento de Engenharia Rural da Faculdade de Ciências Agronômicas, em Botucatu, na região centro oeste do Estado de São Paulo ( $22^{\circ} 5^{\prime}$ S, $48^{\circ} 26^{\prime}$ W, e altitude de $786 \mathrm{~m}$ ). O delineamento experimental utilizado foi o de blocos casualizados em esquema $4 \times 2$, com quatro repetições. Os fatores foram: manejo da irrigação por tensiometria (TS), pelo balanço hídrico baseado no tanque classe A, (TCA), baseado na equação Penman-Monteith (PM) e testemunha não irrigada em dois sistemas de plantios: semeadura direta e convencional. Este trabalho teve como objetivo avaliar os teores de nutrientes presentes nos grãos após a colheita, em dois sistemas de semeadura irrigado, sob diferentes métodos de manejo da irrigação. Os resultados não foram significativos para os macronutrientes $\mathrm{N}, \mathrm{P}, \mathrm{K}, \mathrm{Ca}, \mathrm{Mg}, \mathrm{S}$ e micronutrientes $\mathrm{B}$ e $\mathrm{Zn}$ respectivamente. $\mathrm{O} \mathrm{Cu}, \mathrm{Fe}$ e $\mathrm{Mn}$ foram significativos ao teste de Tukey $5 \%$ obtidas pelo programa Sisvar. O manejo da irrigação proporcionou aumento da produtividade dos grãos $\mathrm{kg} \mathrm{ha}^{-1}$, enquanto que o teor de nutrientes não se alterou.
\end{abstract}

Palavras-chave: Phaseolus vulgaris L., tanque classe A, sistemas de cultivo.

\footnotetext{
${ }^{1}$ Tecnólogo em Irrigação e Drenagem. Pós-Doutorando em Ciências Agrárias - Agronomia, Instituto Federal Goiano - Câmpus Rio Verde, Rodovia Sul Goiana, Km 01, CEP: 75.901-170, Rio Verde - GO, e-mail: josejoaquimcarvalho@yahoo.com.br

${ }^{2}$ Eng. Agrônomo. Mestrando em Ciências Agrárias - Agronomia, IFG - Câmpus Rio Verde, e-mail: nelmiciofurtado@gmail.com

${ }^{3}$ Graduando em agronomia. IFG - Câmpus Rio Verde, e-mail: diego.ma1994@gmail.com.

${ }_{5}^{4}$ Eng. Ambiental. Mestrando em Ciências Agrárias - Agronomia, IFG - Câmpus Rio Verde.

5 Eng. Agrônomo. Mestrando em Ciências Agrárias - Agronomia, IFG - Câmpus Rio Verde, e-mail: fernandonobrecunha@hotmail.com

${ }^{6}$ Eng. Agrônomo, Prof. Dr. em Agronomia, IFG - Câmpus Rio Verde, e-mail: marconibt@gmail.com
} 


\title{
PRODUCTIVITY AND NUTRIENT LEVELS IN GRAINS BEAN UNDER DIFFERENT SOIL MANAGEMENT AND IRRIGATION
}

\begin{abstract}
In irrigated crops, a major factor is determining the depth of water to replenish the losses due to evaporation, with consequent improvement of production efficiency. Within this context it becomes evident the need for management of water applied by irrigation. The aim of this study was to compare the performance of three methods of irrigation in the bean, using trickle irrigation systems and conventional tillage, and evaluate the content of nutrients in the grain after harvest. The work was conducted at Lageado, Botucatu - SP Brazil. The methods were evaluated tensiometer, Class A pan and Penman-Monteith. The seeding was done in 09/2008 cultivar BRS Pontal. We used $214 \mathrm{~kg} \mathrm{ha}^{-1}$ of 8-28-16+0.5\% $\mathrm{Zn}$ as a function of soil test and expected productivity. Fertilization consisted of $70 \mathrm{~kg}$ ha- $1 \mathrm{~N}$ as urea and $1 \mathrm{~kg} \mathrm{ha}^{-1} \mathrm{~B}$, in three applications. The results were not significant for the macronutrients $\mathrm{N}, \mathrm{P}, \mathrm{K}, \mathrm{Ca}, \mathrm{Mg}, \mathrm{S}$ and micronutrients $\mathrm{B}$ and $\mathrm{Zn}$ respectively. The $\mathrm{Cu}, \mathrm{Fe}$ and $\mathrm{Mn}$ were significant Tukey $5 \%$ obtained by Sisvar. The management of irrigation increased the grain yield $\mathrm{kg} \mathrm{ha}^{-1}$, whereas the nutrient content has not changed.
\end{abstract}

Key words: Phaseolus vulgaris L., class A pan, cropping systems.

\section{INTRODUÇÃO}

Dentre os tipos de feijão o carioca é o mais cultivado no território brasileiro, apresentando massa de 23 a 25 gramas a cada 100 grãos. Este possui uma coloração atrativa tendo predominância de cor creme com rajas marrons (RAMALHO \& ABREU, 2006).

As lavouras irrigadas caracterizam-se pela intensificação dos cultivos, e por consequência, uma intensa utilização do solo. Assim, deve-se dar atenção especial às culturas utilizadas, à água da irrigação e ao método de manejo da irrigação. Dentre os métodos utilizados para estimar o requerimento de água pela cultura, cita-se o tanque classe A, o tensiômetro e o manejo pelo modelo de Penman-Monteith.

O manejo adequado do solo aliado ao manejo adequado de irrigação permite obter rendimento elevado, nos diferentes ambientes brasileiros, quando comparado com a produtividade média nacional quanto à média no estado São Paulo que são de $763 \mathrm{~kg} \mathrm{ha}^{-1}$ e 1.856 $\mathrm{kg} \mathrm{ha}^{-1}$, respectivamente para a safra 2011/2012. Esses valores de produtividade tendem a aumentar para a safra de 2012/2013, pois no levantamento feito pela CONAB em agosto de 2013 esses valores já foram superiores com 866 $\mathrm{kg} \mathrm{ha}^{-1}$ e $1.901 \mathrm{~kg} \mathrm{ha}^{-1}$, respectivamente, um aumento de $11,9 \%$ para média nacional e de 2,4\% para média do estado de São Paulo (CONAB, 2013).

Visto a questão socioeconômica, têm-se a importância do cultivo do feijão, com adoção de técnicas que garantem alta produtividade e qualidade do produto final, dentre as principais técnicas destacam-se, o manejo do solo e da irrigação.

Sistema de plantio direto (SPD) associado com uso de sistema de irrigação é uma estratégia de grande importância para agricultura irrigada, uma vez que, a palhada contribui diretamente na redução de água aplicada e consequentemente no aumento de produtividade. Quando irrigado em 


\section{PRODUTIVIDADE E TEORES DE NUTRIENTES EM GRÃOS DE FEIJÃO SOB DIFERENTES MANEJO DO SOLO E DA IRRIGAÇÃO}

SPD, a cobertura morta presente na superfície do solo exprime uma diminuição da evaporação de água no solo, e essa alteração, aumenta a disponibilidade de água as plantas (BIZARI, 2011).

Em termos conservacionistas, o SPD é uma alternativa na redução de perdas de solo. ANA, (2010), mostra que o SPD reduz as perdas de solo em até $76 \%$ e de água em até $69 \%$ com relação ao sistema de plantio convencional.

Nos diferentes agroecossistemas, o feijoeiro desempenha produtividades superiores a $3.000 \mathrm{~kg} \mathrm{ha}^{-1}$, sob cultivo irrigado associado ao balanço da disponibilidade de nutrientes $\mathrm{e}$ seleção de cultivares com potencial produtivo acima de $4.000 \mathrm{~kg} \mathrm{ha}^{-1}$ (FARINELLI \& LEMOS, 2010).

Diante da necessidade de produção em maior quantidade e qualidade. É exigido pela comunidade científica, novos conhecimentos sobre as reais exigências hídricas das culturas (SANTANA et al., 2009). Para as determinações das reposições hídricas, e por consequência, uso eficiente de água, é importante a utilização do método de irrigação que estabeleça o momento e a quantidade de água ideal durante o ciclo da cultura.

A necessidade hídrica do feijoeiro pode ser manejada por tensiometria, em que, são aferidas, medidas de tensão de água do solo, e assim aplicados cálculos indiretos para estimação. Este instrumento tem sido indicado como excelente método no manejo de irrigação do feijoeiro (LOPES et al., 2004).

A possibilidade de subestimação ou superestimação da quantidade ideal de água a ser aplicada à cultura, pelos métodos PM e TCA, são devido às suas particularidades específicas em determinadas regiões (CARVALHO et al., 2011). Os métodos da tensiometria e tanque classe A não necessitam de dados meteorológicos, enquanto o método de PM necessita de maior número de dados de estações meteorológicas e é recomendada pela FAO como método padrão de estimativa da evapotranspiração (REIS et al., 2007).

A produtividade de grãos do feijão comum é influenciada pelo regime hídrico, o qual pode afetar o crescimento e desenvolvimento da planta e, consequentemente, a absorção e translocação de nutrientes. Nesse sentido poucos são os estudos relacionados aos teores de nutrientes em grãos de feijão comum, em condições de sequeiro e irrigado tanto no sistema semeadura direta e convencional.

Este trabalho teve como objetivo comparar os teores de macronutrientes $\mathrm{N}, \mathrm{P}, \mathrm{K}, \mathrm{Ca}, \mathrm{Mg}$ e $\mathrm{S}$ e micronutrientes $\mathrm{B}, \mathrm{Zn}, \mathrm{Cu}, \mathrm{Fe}$ e $\mathrm{Mn}$ presentes no grão de feijão após a colheita e avaliar sua produção sob diferentes métodos de manejo da irrigação nos sistemas PD e PC utilizando a irrigação localizada.

\section{MATERIAL E MÉTODOS}

O experimento foi conduzido na área experimental do Departamento de Engenharia Rural da Faculdade de Ciências Agronômicas, em Botucatu, na região centro oeste do Estado de São Paulo que se encontra a uma altitude de 786 metros.

De acordo com Cepagri (2010), pela classificação de Köppen, o tipo climático é o Cwa, caracterizado como clima temperado quente (mesotérmico) com chuvas no verão e seca no inverno. O período seco compreende os meses de abril a agosto, e a estação chuvosa compreende os meses de setembro a março, sendo o mês de janeiro o mais chuvoso, com 
uma pluviosidade total anual média de $1.314 \mathrm{~mm}$ e temperatura média mensal de $19,4^{\circ} \mathrm{C}$.

A temperatura média diária do mês mais frio (julho) é de aproximadamente $17,1^{\circ} \mathrm{C}$ e a do mês mais quente (fevereiro) é de $23^{\circ} \mathrm{C}$ (CUNHA; MARTINS, 2009).

O solo da área experimental é classificado como Nitossolo Vermelho Distroférrico, textura argilosa (EMBRAPA, 2006).

As análises química e física do solo e granulométrica, foram realizadas no Laboratório de Fertilidade do Solo da FCA, do Departamento de Solos e Recursos Ambientais, da FCA/UNESP - Botucatu, de acordo com a metodologia de Raij et al. (2001), enquanto as frações granulométricas do solo (areia total, silte e argila) e a densidade do solo foram realizadas pela metodologia de EMBRAPA (1997).

A adubação foi procedida com base em análise do solo e recomendação de Raij et al., (2001), sendo $214 \mathrm{~kg} \mathrm{ha}^{-1}$ de $\mathrm{N}, \mathrm{P}_{2} \mathrm{O}^{5}, \mathrm{~K}_{2} \mathrm{O}+\mathrm{Zn}$ da fórmula (8-28-16-0,5) aplicada no sulco da semeadora e $70 \mathrm{~kg} \mathrm{ha}^{-1}$ de $\mathrm{N}$, na forma de ureia, aos 25 dias após emergência (DAE) e $1 \mathrm{~kg} \mathrm{ha}^{-1}$ de micronutriente Boro na forma de acido bórico a 17\%, parcelado em três aplicações aos 30; 35 e 40 DAE.

Tabela 1. Características químicas nas áreas de semeadura direta e convencional.

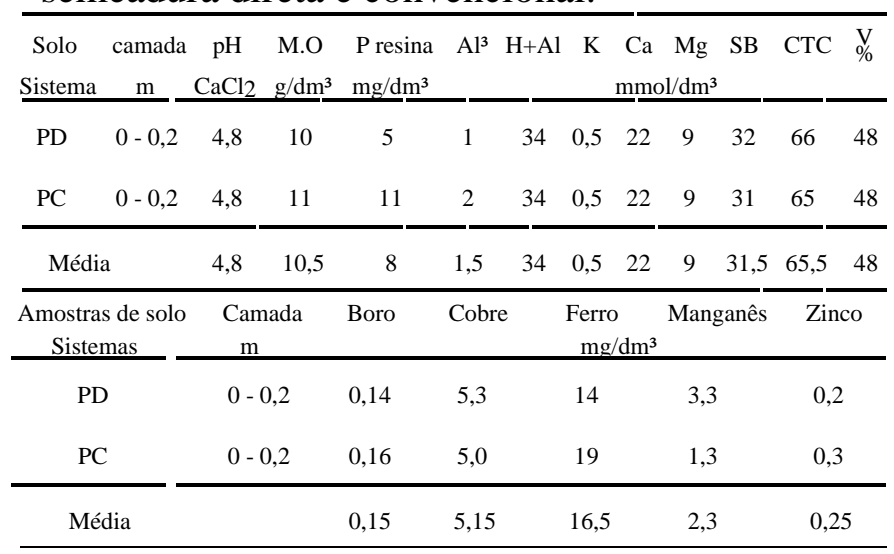

A cultivar possui características de reação intermediaria à ferrugem e ao crestamento bacteriano comum, sendo suscetível à mancha angular, mosaico dourado, maior resistência à antracnose, alto potencial produtivo, ciclo da emergência à maturação fisiológica 87 dias, uniformidade de coloração de grão, massa de 100 grãos 26,1 gramas, e excelentes culinárias (PELOSO et al., 2005).

As sementes foram tratadas com fungicidas tendo como controle da podridão radicular (Furasin) (Rizoctonia solani) e a antracnose (Colletotrichum lindemuthianum), e inseticidas (Tiametoxam), mosca branca (Bemisia tabaci) e a vaquinha-verde-amarela (Diabrotica speciosa). Também foi aplicado herbicida seletivo para a cultura do feijoeiro.

A cultivar de feijão BRS Pontal, do tipo III, foi semeada em 29 de setembro de semeadora mecânica, no espaçamento de $0,45 \mathrm{~m}$ entre linhas, com 14 sementes por metro, para obtenção de 260 mil plantas por hectare.

No sistema de semeadura direta (SSD) utilizou resto cultural de aveia preta, contendo 3,3 $\mathrm{t} \mathrm{ha}^{-1}$ de palhada na superfície do solo, e no preparo do solo para o sistema de semeadura convencional (SSC), realizou uma aração e duas gradagens com enxada rotativa.

Antes da instalação do experimento foi medida a densidade do solo nas áreas de plantio direto e plantio convencional como descrito na Tabela 2.

Tabela 2. Densidade do solo obtida antes da semeadura e após colheita do feijoeiro na área experimental, nas camadas de $0-0,20 \mathrm{~m}$ e de $0,20-0,40 \mathrm{~m}$

\begin{tabular}{lccrr}
\hline Plantio & \multicolumn{2}{c}{$\begin{array}{c}\text { Densidade inicial }\left(\mathrm{kg} / \mathrm{dm}^{3}\right) \\
(0 \mathrm{a} \mathrm{0,20)}\end{array}$} & $\begin{array}{c}\text { Densidade final }\left(\mathrm{kg} / \mathrm{dm}^{3}\right) \\
(0,21 \mathrm{a} 0,40)\end{array}$ & $\begin{array}{l}(0,20) \\
(0,21 \mathrm{a} 0,40)\end{array}$ \\
\hline PD & 1,45 & 1,47 & 1,59 & 1,53 \\
PC & 1,24 & 1,45 & 1,26 & 1,46 \\
\hline \multicolumn{4}{l}{ Semeadura direta (PD); plantio convencional (PC) }
\end{tabular}

O delineamento experimental utilizado foi o de blocos casualizados em esquema fatorial 
$4 \times 2$, com quatro repetições, utilizando-se a análise conjunta (PIMENTEL-GOMES, 2000). Os fatores constituíram: manejo da irrigação por tensiômetria (TS), tanque classe A, (TCA), equação de Penman-Monteith (PM) e sem irrigação (T0) denominada de testemunha em dois sistemas de plantios, semeadura dieta (SSD) e semeadura convencional (SSC).

A área total do experimento foi de 57 x 19 m (0,108 hectares), as parcelas experimentais possuíam 4 fileiras de $5 \mathrm{~m}$ de comprimento com espaçamentos de 0,45 m entre planta, $1 \mathrm{~m}$ entre linha e $2 \mathrm{~m}$ entre blocos. Sendo a área total da parcela de $1,8 \mathrm{~m} \mathrm{x} 5 \mathrm{~m}$ totalizando $9 \mathrm{~m}^{2}$. Eliminou-se das avaliações um metro em todas extremidades das parcelas. A emergência total das plântulas ocorreu aos 7 dias após semeadura.

Para o controle de plantas daninhas, utilizou-se método químico, com herbicida especifico a cultura do feijoeiro, aplicados na pós-emergência, com dosagens de acordo com o fabricante. Constatou ocorrência de plantas daninhas, de folha larga: picão preto (Bidens pilosa L.), leiteiro (Euphorbia heterophilla), língua de vaca (Rumex crispus), e a corda de viola (Ipomoea spp); e as de folhas estreitas: brachiaria (Brachiaria decumbens), tiririca (Ciperus rotundus) e o capim pé de galinha (Eleusine indica (L) Gaerten).

Adotou-se o sistema de irrigação localizada, utilizando-se o gotejo com emissores no espaçamento de $0,2 \mathrm{~m}$, e vazão de $1,18 \mathrm{~L} \mathrm{~h}^{-1}$ por emissor. As linhas laterais constituíram de mangueiras gotejadoras distribuídas nas entrelinhas do feijoeiro, e a pressão de serviço de trabalho utilizado na entrada das mangueiras foi de 10 metros de coluna d'água (mca), de acordo com a especificação do fabricante.

Foi considerada a eficiência do sistema de irrigação na ordem de 90\%. Considerando profundidade efetiva do sistema radicular de 0,3 m, a lâmina de água total necessária em cada irrigação foi de $11 \mathrm{~mm}$ para o SSD e $10 \mathrm{~mm}$ para o SSC.

A lâmina aplicada foi realizada utilizandose um conjunto de moto-bomba de $1 \mathrm{cv}$, filtro de tela, registro e manômetro acoplado ao sistema de irrigação.

Foram realizadas irrigações quando os TS de mercúrio indicavam $30 \mathrm{kPa}$ (EPAMIG, 2008; STONE et al., 2006). As leituras dos TS foram feitas diariamente, durante todo o ciclo fenológico da cultura. As irrigações tiveram início em 14 de outubro de 2008 em ambos os sistemas de plantio, sendo a lâmina aplicada com $1 \mathrm{~mm}$ a mais de diferença para o sistema semeadura direta em relação ao plantio convencional de acordo com a curva característica de retenção de água no solo.

Para calcular a lâmina de irrigação no método TS, considerou-se o intervalo de umidade compreendido entre a tensão de irrigação $30 \mathrm{kPa}$ e a capacidade de campo, correspondente ao valor de $10 \mathrm{kPa}$. Os valores da umidade do solo, em base volumétrica, correspondentes ao momento de irrigar e à capacidade de campo foram, respectivamente, de $31,25 \%$ e $34,47 \%$ para o SSD, e respectivamente, de $25,47 \%$ e $28,24 \%$ para o SSC.

As lâminas de irrigação foram estimadas pela equação: $\mathrm{ETc}=\mathrm{ETo} * \mathrm{kc}$, em que ETo foi determinada com base no modelo de PenmamMonteith, com os dados obtidos na estação meteorológica do Departamento de Recursos Naturais - Ciências Ambientais, situada a 300 metros da área experimental.

Os coeficientes de cultivos utilizados em PM e TCA foram recomendados por Doorenbos \& Kassam (1994), conforme os estágios fenológicos de estabelecimento $(0,35)$ desenvolvimento vegetativo $(0,75)$, 
florescimento $(1,10)$, frutificação $(0,70)$ e maturação $(0,30)$.

O coeficiente do TCA foi determinado segundo metodologia proposta por Snyder (1992). O balanço hídrico foi realizado de forma simplificada, levando-se em consideração a curva característica do solo, precipitação pluviométrica, irrigação e a evapotranspiração de referência.

A colheita foi realizada entre os dias $22 \mathrm{e}$ 29 de dezembro, em duas fileiras da área útil da parcela considerando $3 \mathrm{~m}$ de comprimento. As plantas foram submetidas à trilha manual. Em seguida quantificou a umidade dos grãos e as mesmas foram corrigidas para $0,13 \mathrm{~kg} \mathrm{ha}^{-1}$ (base úmida), obtendo-se a produtividade de grãos, conforme metodologia de (BRASIL, 1992).

Retiraram-se amostras de grãos de cada parcela, tendo como objetivo obter o teor nutricional de macronutrientes $(\mathrm{N}, \mathrm{P}, \mathrm{K}, \mathrm{Ca}, \mathrm{Mg}$ e S) e micronutrientes (B, $\mathrm{Cu}, \mathrm{Fe}, \mathrm{Mn}$ e $\mathrm{Zn}$ ) após a colheita. Os grãos em cada parcela foram secos em estufa com circulação forçada de ar a 60-70 ${ }^{\circ} \mathrm{C}$, até atingir massa constante, e, em seguida, foram moídos e submetidos à análise, conforme metodologia de Malavolta et al. (1997).

Foi realizada análise de variância, e quando significativo as variáveis foram submetidas ao teste de Tukey ao nível de 5\% de significância pelo programa Sisvar 5.3. (FERREIRA, 2011).

\section{RESULTADOS E DISCUSSÃO}

A ocorrência da precipitação pluviométrica acumulada foi de $248,9 \mathrm{~mm}$ no período de $29 \mathrm{de}$ outubro a 29 de dezembro de 2009 (Tabela 3). Os tratamentos que foram utilizados os métodos TS, PM e TCA além de irrigação receberam as precipitações pluviométricas e a testemunha (T0) recebeu apenas os 248,9 mm devido unicamente a precipitação pluviométrica (sem irrigação).

As lâminas de irrigação no ciclo do feijoeiro foram menores utilizando o método de manejo com o TS em ambos os sistemas de plantios PD e PC, já as maiores médias foram utilizando o TCA (Tabela 3).

Tabela 3. Precipitações pluviométricas e lâmina de irrigação no ciclo do feijoeiro.

\begin{tabular}{llllll}
\hline Manejo & Prec. $(\mathrm{mm})$ & \multicolumn{4}{c}{ Irrigação $(\mathrm{mm})$} \\
\cline { 3 - 6 } & & TO & TS & PM & TCA \\
\hline PD & 248,9 & 0 & 110 & 187 & 192,6 \\
PC & 248,9 & 0 & 120 & 190 & 195,7 \\
\hline
\end{tabular}

(TO) Testemunha; (TS) Tensiômetro; (PM) PenmamMonteith; (TCA) Tanque Classe A.

A ocorrência da má distribuição da precipitação pluviométrica, causou a necessidade da irrigação, devido à ocorrência de veranicos no período, principalmente na fase de maior exigência hídrica da planta que é a fase reprodutiva, assegurando a produção.

As irrigações foram realizadas até os 64 DAE e após não houve necessidade em decorrência das precipitações pluviométricas ocorridas e também porque as plantas já se encontravam em fase final de ciclo, ou seja, nas análises de produtividade.

A produtividade de grãos do feijão também é influenciada pelo regime hídrico, o qual pode afetar o crescimento do sistema radicular e, consequentemente, a absorção e translocação de nutrientes (GOMES et al., 2000).

$\mathrm{O}$ fornecimento adequado de nutrientes contribui, de forma significativa, tanto no aumento da produtividade como no aumento do custo da produção. Nesta situação, a otimização de eficiência nutricional é fundamental para ampliar a produtividade e reduzir o custo de produção. Vários fatores, como clima, solo, planta e suas interações, afetam a absorção e a 
utilização de nutrientes pelas plantas. Para a eficiência máxima de nutrientes, esses fatores devem estar no nível ótimo durante o desenvolvimento da cultura e trabalhos como este demonstra que existem grandes potenciais de se aumentar a eficiência nutricional através do manejo adequado dos componentes do sistema de produção.

Todos os manejos da irrigação proporcionaram aumento na produtividade dos grãos, obtendo resultados significativos em relação à testemunha.

Destaca-se o manejo da irrigação com TCA, que apresentou as maiores médias de produtividade de grãos de feijão, nos dois sistemas de plantio (Tabela 4).

As testemunhas resultaram em redução média de $50,7 \%$ e $51,02 \%$ na produtividade de grãos respectivamente, para os sistemas PD e PC em relação ao TCA.

Tabela 4. Produtividade média de feijão BRS Pontal.

\begin{tabular}{ccccc}
\hline Manejo & \multicolumn{4}{c}{ Manejo da irrigação } \\
\cline { 2 - 5 } & TO & TS & PM & TCA \\
\hline PD & $1.717 \mathrm{bA}$ & $3.212 \mathrm{aA}$ & $3.267 \mathrm{aA}$ & $3.385 \mathrm{aA}$ \\
PC & $2.026 \mathrm{cA}$ & $3.391 \mathrm{bA}$ & $3.638 \mathrm{abA}$ & $3.971 \mathrm{aA}$
\end{tabular}

$\overline{\text { Médias seguidas de letras distintas, maiúsculas nas linhas e }}$ minúsculas nas colunas, diferem entre si, pelo teste de Tukey ( $\mathrm{P}<0,05)$, (PD) Plantio direto; (PC) plantio convencional; (TO) testemunha; (TS) Tensiômetro; (PM) Penman-Monteith; (TCA) Tanque Classe A.

De acordo com o estudo, verifica-se que o acúmulo de nutrientes em grãos de feijão cv BRS Pontal em função do manejo de solo e do método de manejo de irrigação constataram que os macros e micronutrientes acumularam na seguinte ordem: $\mathrm{N}>\mathrm{K}>\mathrm{Ca}>\mathrm{Mg}>\mathrm{P} \quad$ e $\mathrm{Fe}>\mathrm{B}>\mathrm{Mn}>\mathrm{Zn}>\mathrm{Cu}$. Estes resultados verificaram também que o $\mathrm{N}$ e o $\mathrm{K}$ são os nutrientes exportados em maior quantidade pelos grãos, em relação à quantidade acumulada na matéria seca de grãos. Estes resultados são semelhantes em partes em relação ao estudo do teor e acúmulo de nutrientes por plantas de feijão caupi em função do fósforo e da saturação por bases realizado por Fonseca et al. (2011) constataram que os macros e micronutrientes acumulam na seguinte ordem: $\mathrm{N}>\mathrm{K}>\mathrm{Ca}>\mathrm{Mg}>\mathrm{P}$ e $\mathrm{Fe}>\mathrm{B}>\mathrm{Mn}>\mathrm{Zn}>\mathrm{Cu}$. Estes autores verificaram também que o $\mathrm{N}$ e o $\mathrm{P}$ são os nutrientes exportados em maior quantidade pelos grãos, em relação à quantidade acumulada na matéria seca da parte aérea.

$\mathrm{Na}$ Tabela 5 são mostrados valores dos macro e micronutrientes presentes nos grãos com relação aos sistemas de manejo. Houve significância para os macronutrientes $\mathrm{Ca}$ e $\mathrm{Mg}$, onde os maiores valores encontrados foram para o sistema de PC sendo de 6,10 e de $2,25 \mathrm{~g} \mathrm{~kg}^{-1}$ para $\mathrm{Ca}$ e $\mathrm{Mg}$ respectivamente, e os valores de 5,35 e de $2,13 \mathrm{~g} \mathrm{~kg}^{-1}$ respectivamente para o PD. Isso pode ser explicado pelo fato deste sistema melhor disponibilizar nutrientes para a cultura, já que possui maior número de macro $\mathrm{e}$ microporos, diferente do sistema de PD que a porosidade é menor. Os valores de densidade iniciais encontrados foram de $1,24 \mathrm{Mg} \mathrm{m}^{-3}$ para a localidade do PC e de $1,45 \mathrm{Mg} \mathrm{m}^{-3}$ para PD (Tabela 2). A densidade encontrada para o PD pode favorecer a inibição da absorção de nutrientes, pois está acima de $1,40 \mathrm{Mg} \mathrm{m}^{-3}$ que é o valor encontrado por Marschner (1986) que limita a absorção de nutrientes das plantas dependendo do tipo de solo e da umidade. Silva e Rosolem (2001) avaliando a compactação do solo na absorção de macronutrientes em soja verificaram que houve redução no acúmulo de $\mathrm{Ca}$ e $\mathrm{Mg}$ com a densidade acima de $1,36 \mathrm{Mg} \mathrm{m}^{-3}$.

Segundo Vieira (2006) com a crescente utilização do sistema plantio direto, os atributos físicos do solo tem sido modificados, 
necessitando de mais estudos referentes à densidade do solo, a qual mostra uma tendência de aumento nos primeiros anos de cultivo e, com o passar dos anos, apresenta uma diminuição. Esses efeitos foram observados por Corsini e Ferraudo (1999), que avaliando o efeito de sistemas de cultivos na densidade do solo, concluíram que nos três primeiros anos de plantio direto ocorre aumento da densidade do solo e diminuição da porosidade, reduzindo o desenvolvimento radicular, e que somente a partir do quinto ano agrícola esses parâmetros começam a se restabelecer a níveis normais de cultivo.

Tabela 5. Teor médio de nutrientes presentes em grãos de feijão Pontal BRS.

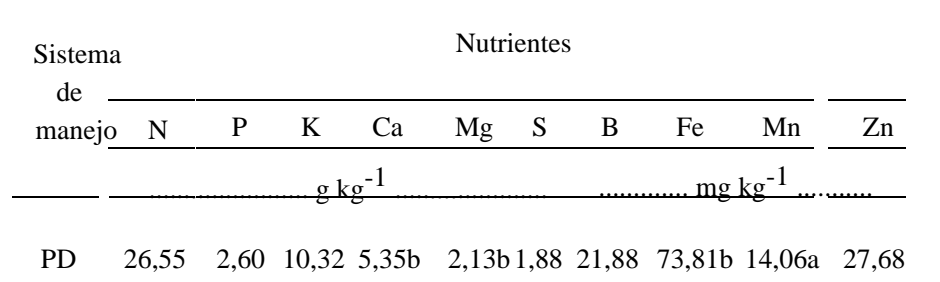

PC $\quad 26,48 \quad 2,58 \quad 9,96 \quad 6,10 \mathrm{a} \quad 2,25 \mathrm{a} 1,98 \quad 23,26 \quad 82,25 \mathrm{a} \quad 12,62 \mathrm{~b} \quad 29,50$

Médias seguidas de letras distintas, maiúsculas nas linhas e minúsculas nas colunas, diferem si, pelo teste de Tukey $(\mathrm{P}$ $<0,05)$, (PD) Plantio direto; (PC) plantio convencional; (C.V) Coeficiente de variação; (TO) Testemunha; (PM) Penman-Monteith ; (TS) Tensiômetro; (TCA) Tanque Classe A.

Houve também significância para os micronutrientes $\mathrm{Fe}$ e $\mathrm{Mn}$, onde para o Fe obtevese o maior valor para PC sendo de $82,25 \mathrm{mg} \mathrm{kg}^{-1}$ e de $73,81 \mathrm{mg} \mathrm{kg}^{-1}$ para o PD. Isso pode ser explicado pelo fato de o solo da área do PC disponibilizar maiores quantidades desse nutriente para planta em relação ao PD como demonstrado na tabela 1 que expõe valores da análise química realizada nestes solos. Já para o Mn os valores iniciais encontrados na análise química se inverteram sendo $3,3 \mathrm{mg} \mathrm{dm}^{-3}$ para o
PD e $1,3 \mathrm{mg} \mathrm{dm}^{-3}$ para o PC (Tabela 1 ), mais que o dobro de nutriente disponível. Isso explica o maior valor de $\mathrm{Mn}$ acumulado pelos grãos no sistema de PD. Estes resultados mostram a importância da irrigação no incremento na produtividade, bem como a mantença dos teores dos nutrientes presentes nos grãos.

Conforme mostrado na Tabela 6 houve diferença significativa apenas para os nutrientes $\mathrm{N}$, Ca e Fe. Para o $\mathrm{N}$ o maior valor encontrado foi de $30,63 \mathrm{~g} \mathrm{~kg}^{-1}$ no manejo T0, os valores dos manejos PM, TS e TCA foram menores e se diferiram estatisticamente. A partir dos valores de teores médios por grãos obtém-se a quantidade de $\mathrm{N}$ acumulado, os quais foram 57 , $31 ; 88,66 ; 79,67$ e $94,23 \mathrm{~kg} \mathrm{ha}^{-1}$ para T0, PM, TS e TCA respectivamente. Esse resultado é muito parecido com o encontrado por Pessoa et al. (1996) onde, verificou-se o menor valor acumulado por ha ${ }^{-1}$ para o T0.

Tabela 6. Teor médio de nutrientes presentes em grãos de feijão Pontal BRS

\begin{tabular}{|c|c|c|c|c|c|c|c|c|c|c|}
\hline \multirow{2}{*}{$\begin{array}{c}\text { Manejo da } \\
\text { irrigação }\end{array}$} & \multicolumn{10}{|c|}{ Nutrientes } \\
\hline & $\mathrm{N}$ & $\mathrm{P}$ & $\mathrm{K}$ & $\mathrm{Ca}$ & $\mathrm{Mg}$ & $S$ & B & $\mathrm{Fe}$ & $\mathrm{Mn}$ & $\mathrm{Zn}$ \\
\hline & & & & $\mathrm{g} \mathrm{kg}^{-1}$ & & & & $m$ & $\mathrm{~kg}^{-1}$ & \\
\hline T0 & $30,63 \mathrm{a}$ & 2,59 & 10,17 & $4,65 \mathrm{~b}$ & 2,11 & 1,96 & 21,33 & $83,62 \mathrm{a}$ & 14,37 & 30,25 \\
\hline PM & $25,68 \mathrm{~b}$ & 2,62 & 10,20 & $5,72 \mathrm{ab}$ & 2,16 & 1,93 & 22,64 & $75,75 \mathrm{ab}$ & 13,62 & 28,50 \\
\hline TS & $24,13 \mathrm{~b}$ & 2,51 & 9,70 & $6,55 \mathrm{a}$ & 2,25 & 1,92 & 23,19 & $80,75 \mathrm{ab}$ & 12,87 & 27,75 \\
\hline TCA & $25,62 \mathrm{~b}$ & 2,65 & 10,51 & $5,98 \mathrm{ab}$ & 2,25 & 1,91 & 23,13 & $72,00 \mathrm{~b}$ & 12,50 & 27,87 \\
\hline
\end{tabular}

Médias seguidas de letras distintas, maiúsculas nas linhas e minúsculas nas colunas, diferem si, pelo teste de Tukey ( $\mathrm{P}$ $<0,05$ ), (PD) Plantio direto; (PC) plantio convencional; (C.V) Coeficiente de variação; (TO) Testemunha; (PM) Penman-Monteith ; (TS) Tensiômetro; (TCA) Tanque Classe A.

Para Ca obteve-se o maior valor para TS com 6,55 $\mathrm{g} \mathrm{kg}^{-1}$ diferindo-se estatisticamente apenas da testemunha (T0). Os valores de T0, 
PM e TCA não diferiram entre si e o mesmo aconteceu entre os feijões irrigados (PM, TS e TCA). Guzmán-Maldonado et al. (2000) encontraram valores próximos aos da testemunha com cerca de $4,06 \mathrm{~g} \mathrm{~kg}^{-1}$.

Para $\mathrm{Fe}$ encontrou-se na testemunha $\mathrm{o}$ maior valor $\left(83,62 \mathrm{mg} \mathrm{kg}^{-1}\right)$ que difere estatisticamente apenas do manejo de irrigação TCA. Valor próximo a esse foi encontrado por Pessoa et al. (2011) avaliando teores de ferro em feijão comum descobriu o valor de $96 \mathrm{mg} \mathrm{kg}^{-1}$ para primeiro ano de avaliação. Os valores de PM, TS e TCA não se diferiram entre si, mas diferiram em relação à testemunha.

Para médios de nutrientes presentes em grãos de feijão após colheita para os micronutrientes $\mathrm{B}$ e $\mathrm{Zn}\left(\mathrm{mg} \mathrm{kg}^{-1}\right)$, não foram estatisticamente diferentes nos sistemas de PD e PC e quando utilizaram se irrigação, para os métodos de manejo TS, PM, TCA comparados com TO (Tabela 6).

Os teores de Ferro presentes no grão em (mg $\mathrm{kg}^{-1}$ ) não foram estatisticamente significativos entre os sistemas PD e PC. Enquanto aos métodos de manejo da irrigação utilizado estes foram significativos tanto no PD quantos no PC.

Quanto aos teores de Manganês caracterizado no grão em $\left(\mathrm{mg} \mathrm{kg}^{-1}\right)$, estes não foram estatisticamente significativos entre os sistemas PD e PC, enquanto para os métodos de manejo da irrigação foram significativos tanto no PD quantos no PC.

Teores médios de $\mathrm{Cu}$ analisados nos grãos de feijão em $\left(\mathrm{mg} \mathrm{kg}^{-1}\right)$ foram significativos entre os sistemas de PD e PC, para os métodos PM e TCA (Tabela 7). Para o sistema semeadura direta não houve diferença significativa entre os métodos avaliados e testemunha. Portanto no sistema convencional o método TCA difere se estatisticamente dos manejo TO e PM e não diferindo do TS. As variações de $\mathrm{Cu}$ foram de 7,5 a 10 mg $\mathrm{kg}^{-1}$, sendo estes valores semelhantes aos teores considerados adequados para o feijão caupi com uma faixa entre 5 e $7 \mathrm{mg}$ $\mathrm{kg}^{-1}$, segundo Malavolta et al. (1997), porém, neste trabalho encontram abaixo dos valores obtidos por (FONSECA, 2011).

Tabela 7. Teor médio de nutrientes presentes em grãos de feijão Pontal BRS.

\begin{tabular}{ccccc}
\hline \multirow{2}{*}{$\begin{array}{c}\text { Sistema de } \\
\text { Manejo }\end{array}$} & \multicolumn{4}{c}{ Manejo da Irrigação } \\
\cline { 2 - 5 } T0 & PM & TS & TCA \\
\hline PD & $8,25 \mathrm{aA}$ & $9,50 \mathrm{aA}$ & $8,25 \mathrm{aA}$ & $8,25 \mathrm{bA}$ \\
PC & $7,50 \mathrm{aB}$ & $7,75 \mathrm{bB}$ & $8,75 \mathrm{aAB}$ & $10,00 \mathrm{aA}$ \\
\hline
\end{tabular}

Médias seguidas de letras distintas, maiúsculas nas linhas e minúsculas nas colunas, diferem si, pelo teste de Tukey ( $\mathrm{P}$ $<0,05$ ), (PD) Plantio direto; (PC) plantio convencional; (C.V) Coeficiente de variação; (TO) Testemunha; (PM) Penman-Monteith ; (TS) Tensiômetro; (TCA) Tanque Classe A

\section{CONCLUSÃO}

Vários fatores podem contribuir para os teores dos nutrientes se acumular no grão de feijão, dentre eles o potencial hidrogeniônico $(\mathrm{pH})$, disponibilidade de nutrientes no solo, disponibilidade hídrica para a cultura e densidade do solo. O manejo do solo e da irrigação interfere na produtividade e no teor de macro e micronutrientes dos grãos de feijão.

Houve uma tendência de maior acúmulo de nutrientes no sistema semeadura convencional em relação ao sistema plantio em ambos os sistema de manejo de irrigação, visto que este está correlacionado a produtividade.

O acúmulo de nutrientes em grãos de feijão cv BRS Pontal em função do manejo de solo e do método de manejo de irrigação 
constataram que os macros e micronutrientes acumularam na seguinte ordem: $\mathrm{N}>\mathrm{K}>\mathrm{Ca}>\mathrm{Mg}>\mathrm{P}$ e $\mathrm{Fe}>\mathrm{B}>\mathrm{Mn}>\mathrm{Zn}>\mathrm{Cu}$. Sendo N e o $\mathrm{K}$ os nutrientes exportados em maior quantidade pelos grãos.

\section{AGRADECIMENTOS}

Os autores agradecem ao $\mathrm{CNPq}$ pela concessão da bolsa de mestrado ao primeiro autor; à Empresa Petroisa pela doação do manômetro e mangueiras gotejadoras; e ao Dr. Leonardo Cunha Melo, pesquisador da Embrapa Arroz e Feijão, pela doação das sementes de feijão cv. BRS Pontal

\section{REFERÊNCIAS BIBLIOGRÁFICAS}

ANA. Agência Nacional de Águas. 2010. Conservação de água e solo. <http://www.ana.gov.br/bibliotecavirtual/arquivo s/ANAConservacao_agua_solo_Felix_Domingu es.pdf>.16 Nov. 2013.

BIZARI, D. R.; MATSURA, E. E.; DEUS, F. P.; MESQUITA, M. Diferentes sistemas de manejo do solo no consumo de água do feijoeiro irrigado em Campinas-SP. Revista Brasileira de Agricultura Irrigada, Fortaleza, v.5, n. 3, p.143152, 2011.

BRASIL. Ministério da Agricultura e Reforma Agrária. Secretaria Nacional de Defesa Agropecuária. Departamento Nacional de Produção Vegetal. Coordenação de Laboratório
Vegetal. Regras para análise de sementes. Brasília, DF, 1992. 365p.

CARVALHO, L. G.; RIOS, G. F. A.; MIRANDA, W. L.; CASTRO NETO, P. Evapotranspiração de referência: uma abordagem atual de diferentes métodos de estimativa. Pesquisa Agropecuária Tropical, Goiânia, v.41, n. 3, p. 456-465, 2011.

CEPAGRI. Centro de pesquisas meteorológicas e climáticas aplicadas à agricultura. Clima dos municípios paulistas. Disponível em: <http://www.cpa.unicamp.br>. 13 Nov. 2010.

CONAB. Companhia nacional de abastecimento. Acompanhamento de safra brasileira: grãos. Décimo primeiro levantamento, agosto 2013. Brasília: Conab, 2013. <http://www.conab.gov.br/OlalaCMS/uploads/ar quivos/13_08_09_10_43_44_boletim_portuges_ agosto_2013_port.pdf>. 10 Dez. 2013.

CORSINI P. C.; FERRAUDO, A. S. Efeitos de sistemas de cultivos na densidade e macroporosidade do solo e no desenvolvimento radicular do milho em latossolo roxo. Pesquisa Agropecuária Brasileira, Brasília, v. 34, p. 289298, 1999.

CUNHA, A. R., MARTINS, D. Classificação climática para os municípios de Botucatu e São Manuel, SP. Irriga, Botucatu, v. 14, n. 1, p. 1-11, 2009.

DOORENBOS, J.; KASSAM, A. H. Efeito da água no rendimento das culturas. Roma: FAO, 1994. 306 p. (Estudos FAO; Irrigação e drenagem, 33).

EMBRAPA. Centro Nacional de Pesquisa de Solo. Manual de métodos de análise de solo. 2 
ed., Rio de Janeiro: Embrapa Solos, 1997, 212 p. Embrapa, 2009. p. 47-63.

EMBRAPA. Centro Nacional. Pesquisa em solos. Sistema brasileiro de classificação de Solos. Brasília: Embrapa-SPI; Rio de janeiro: Embrapa solos, 2006. 306p.

FARINELLI, R.; LEMOS, L. B. Produtividade, eficiência agronômica, características nutricionais e tecnológicas do feijão adubado com nitrogênio em plantio direto e convencional. Bragantia, Campinas, v.69, n.1, p.165-172, 2010.

FERREIRA, D. F. Sisvar 5.3: a computer statistical analysis system. Ciência e Agrotecnologia (UFLA), v. 35, n.6, p. 10391042, 2011.

FONSECA, M. R.; FERNANDES, A. R.; SILVA, G. R.; BRASIL, E. C. Teor e acúmulo de nutrientes por plantas de feijão caupi em função do fósforo e da saturação por bases. Revista Ciências Agrárias, v. 53, n.2, p.195-205, 2011.

GOMES, A. A.; ARAÚJO, A. P.; ROSSIELlO, R. O. P.; PIMENTEL, C. Acumulação de biomassa, características fisiológicas e rendimento de grãos em cultivares de feijoeiro irrigado e sob sequeiro. Pesquisa Agropecuária Brasileira, v.35, p.1927-1937, 2000.

GUZMÁN-MALDONADO, S. H.; ACOSTAGALLEGOS, J.; PAREDES-LÓPEZ, O. Protein and mineral content of a novel collection of wild and weedy common bean (Phaseolus vulgaris $L$ ). Journal of the Science of Food and Agriculture, London, v. 80, n. 13, p. 1874-1881, 2000.
LOPES, A. S.; PAVANI, L. C.; CORÁ, J. E.; ZANINI, J. R.; MIRANDA, H. A. Manejo da irrigação (tensiometria e balanço hídrico climatológico) para a cultura do feijoeiro em sistemas de cultivo direto e convencional. Engenharia Agrícola, v.24, p.89-100, 2004.

MALAVOLTA, E.; VITTI. G. C.; OLIVEIRA, S. A. Avaliação do estado nutricional das plantas: princípios e aplicações. 2 ed. Piracicaba: Potafós, 1997. 319 p.

MARSCHNER, H. Mineral nutrition of higher plants. New York: Academic, 1986. 403 p.

EPAMIG. Informações técnicas para o cultivo do feijoeiro-comum na região central brasileira. Viçosa: EPAMIG, 2008. 180.p (Série documentos, n. 42).

DEL PELOSO, M.J.; MELO, L.C.; DE FARIA, L.C.; COSTA, J.C.G.; RAVA, C.A.; CARNEIRO, G.E.S.; SOARES, D.M.; DÍAZ, J.L.C.; ABREU, A.F.B.; DE FARIA, J.C.; SARTORATO, A.; SILVA, H.T.; BASSINELLO, P.Z; ZIMMERMANN, F.J.P. BRS Pontal: nova cultivar de feijoeiro comum, de tipo grão carioca, com alto potencial produtivo. Santo Antônio de Goiás: Embrapa Arroz e Feijão, 2005.p.354-356.

PESSOA, A. C. S.; KELling, C. R. S.; POZZEBON, E. J.; KONIG, O. Concentração e acumulação de nitrogênio, fósforo e potássio pelo feijoeiro cultivado sob diferentes níveis de irrigação. Revista Ciência Rural, Santa Maria, v. 26, n.1, p.69-74, 1996.

PIMENTEL-GOMES, F. Curso de estatística 
experimental. 14. ed. Piracicaba: Desgaspari, 2000. 447 p.

RAIJ, B. VAN. et al. Análise química da fertilidade dos solos tropicais. Campinas: IAC, 2001, 285 p.

RAMALHO, M. A. P.; ABREU. A. F. B. Cultivar. In: VIEIRA, C.; PAULA JUNIOR, T. J.; BORÉN, A. (Eds.). Feijão. 2ed.. Viçosa: UFV, 2006. p. 415 - 436.

REIS, E. F.; BRAGANÇA, R.; GARCIA, G. O.; PEZZOPANE, J. E. M.; TAGLIAFERRE, C. Estudo comparativo da estimativa da evapotranspiração de referência para três localidades do estado do Espírito Santo no período seco. Idesia, v.25, p.75-84, 2007.

SANTANA, M. J.; CARVALHO, J. A.; ANDRADE, M. J. B.; GERVÁSIO, G. G.; BRAGA, J. C.; LEPRI, E. B. Viabilidade técnica e econômica da aplicação de água na cultura do feijoeiro comum (Phaseolus vulgaris L.). Ciências e Agrotecnologia, v.33, p.532-538, 2009.
SILVA, R. H.; ROSOLEM, C. A. Influência da cultura anterior e da compactação do solo na absorção de macronutrientes em soja. Pesquisa Agropecuária Brasileira, Brasília, v. 36, n. 10, p. 1269-1275, 2001.

SNYDER, R. L. Equation for evaporation pan to evapotranspiration conversions. Journal of Irrigation and Drainage Engineering, Reston, v. 118, p. 977-980, 1992.

STONE, L. F.; SILVEIRA, P. M.; MOREIRA, J. A.; BRAZ, A. J. B. P. Evapotranspiração do feijoeiro irrigado em plantio direto sobre diferentes palhadas de culturas de coberturas. Pesquisa Agropecuária Brasileira, Brasília, vol. 41, n. 4, 2006.

VIEIRA, M. L. Propriedades físico-hídricomecânicas do solo e rendimentos de milho submetidos a diferentes sistemas de manejo. 2006. 104 f. Dissertação (Mestrado em Agronomia/Produção Vegetal)-Faculdade de Agronomia e Veterinária, Universidade de Passo Fundo, Passo Fundo, 2006. 